\title{
General Internists as Change Agents: Opportunities and Barriers to Leadership in Health Systems and Medical Education Transformation
}

\author{
Jed D. Gonzalo, MD, MSc ${ }^{7}$ (D), Cynthia H. Chuang, MD, MSc ${ }^{7}$, Susan A. Glod, $M D^{7}$, \\ Brian McGillen, $M D^{2}$, Ryan Munyon, $\mathrm{MD}^{2}$, and Daniel R. Wolpaw, $\mathrm{MD}^{7}$
}

'Division of General Internal Medicine, Penn State College of Medicine, Hershey, PA, USA; ${ }^{2}$ Division of Hospital Medicine, Penn State College of Medicine, Hershey, PA, USA.

Health systems are increasingly engaging in mission development around the quadruple aim of patient experience of care, population health, cost of care, and work-life balance of clinicians. This integrated approach is closely aligned with the education principles and competencies of health systems science (HSS), which includes population health, high-value care, leadership, teamwork, collaboration, and systems thinking. Influenced by health outcomes research, the systems-based practice competency, and the Clinical Learning Environment Review, many medical schools and residency programs are taking on the challenge of comprehensively incorporating these HSS competencies into the education agenda. General internal medicine physicians, inclusive of hospitalists, geriatricians, and palliative and primary care physicians, are at the frontlines of this transformation and uniquely positioned to contribute to and lead health system transformation, role model HSS competencies for trainees, and facilitate the education of a new workforce equipped with HSS skills to accelerate change in healthcare. Although GIM faculty are positioned to be early adopters and leaders in evolving systems of care and education, professional development and changes with academic health systems are required. This Perspective article explores the conceptualization and opportunities to effectively link GIM with healthcare and medical education transformation.

J Gen Intern Med 35(6):1865-9

DOI: $10.1007 / \mathrm{s} 11606-019-05611-5$

(c) Society of General Internal Medicine 2020

\section{BACKGROUND}

With the goal of improving patient outcomes, US healthcare systems are transforming care processes to achieve the quadruple aim of patient experience, population health, cost of care, and the work-life balance of clinicians. ${ }^{1,2}$ This trend has resulted in an increased focus on health systems science

Electronic supplementary material The online version of this article (https://doi.org/10.1007/s11606-019-05611-5) contains supplementary material, which is available to authorized users.

Received August 22, 2019

Revised October 21, 2019

Accepted December 6, 2019

Published online January 2, 2020
(HSS), defined as "the principles, methods, and practice of improving quality, outcomes, and costs of healthcare delivery for patients and populations within systems of medical care."3 The HSS framework includes competencies such as population health improvement, value-based care, leadership, collaboration, and systems thinking. ${ }^{4-7}$ This emerging health system perspective, coupled with the need for dedicated expertise in the care of increasingly sick hospitalized patient populations, has spurred the growth of general internal medicine (GIM) ${ }^{8,9}$ In our working definition of GIM, we include faculty in outpatient internal medicine clinics, hospitalists, geriatricians, and palliative care physicians. GIM physicians practice at the nexus of various aspects of health systems and change, confronting widening disparity gaps and care fragmentation across inpatient, subacute, and outpatient settings. GIM faculty educators often address discontinuities of care that result from increasingly specialized professions, providing expertise in consultation and outcomes research, and innovating in interprofessional collaborative care. All of these activities contribute to the development of a learning health system, one that leverages technology and data to inform care in real time while simultaneously drawing knowledge from care delivery to promote innovation. ${ }^{10}$

Along with their generalist colleagues, GIM physicians commonly navigate their patients through complex and often dysfunctional health systems, requiring development of working knowledge in HSS areas. As a result, GIM physicians are well positioned to find solutions to make the system work better for patients and clinicians and committed to helping junior colleagues learn. One key challenge in this process is that most physicians, including GIM physicians, have not been formally trained to think beyond helping individual patients. ${ }^{11,12}$ Although there has been increasing attention in recent years to systems-based practice (SBP) competency areas, including quality and patient safety, traction to teach HSS in residencies has been slow and variable..$^{13-17}$ Many care settings are not designed to engage physician leaders in these areas, much less other critical areas of HSS. In this Perspective article, we explore the unique positioning of GIM within systems of healthcare and medical education, the accompanying need for faculty development and 
leadership support, and potential opportunities for these goals to be realized.

\section{“NEW" COMPETENCIES IN HEALTH SYSTEMS SCIENCE}

Over the past 20 years, the Accreditation Council for Graduate Medical Education SBP and practice-based learning and improvement (PBLI) competency areas, Clinical Learning Environment Review, and Association of American Medical Colleges (AAMC) have accelerated medical education's focus on systems-related competencies. ${ }^{18-22}$ Specifically, efforts have been made to incorporate patient safety, quality improvement, social determinants of health, and care transitions as integrated components of student and resident education. ${ }^{13,19}$ However, these learning areas reflect a narrow view of systems competencies and often occupy aspirational rather than required competence domains. ${ }^{23}$ To address these gaps, undergraduate (UME), graduate (GME), and continuing medical education (CME) have begun to adopt HSS as a third education pillar, complementing the basic and clinical sciences, which provides a more comprehensive framework than the SBP competency area. ${ }^{5,7,24,25}$ The HSS pillar coalesces previously disconnected competencies to better align trainees' education with the needs of the patients whom they will serve, including population health, social determinants of health, high-value care, leadership, teamwork, and collaboration. ${ }^{4,}$, 26-29 These competency areas are all connected by systems thinking, or the body of knowledge, theory, and tools that allows for the seeing of interrelationships amongst elements, patterns of change, and structures underlying complex situations to produce desired outcomes (Table 1). ${ }^{7,32,33}$ Similar to several other US medical schools, the Penn State College of Medicine has addressed this curricular challenge at every level from UME through CME, with authentic early experiences, classroom learning, practical application in patient care, and mentored projects. ${ }^{4,23,34,35}$ For example, in both the internal medicine (IM) clerkship and residency program, learners are prompted to present cases in a "SOAP-V" format (subjective-objectiveassessment-plan-value), reflect on HSS implications in patient cases, and pursue system improvement projects. ${ }^{36}$ At the faculty level, our HSS academy brings together frontline providers from all disciplines in a year-long curriculum to explore the field and work on HSS-related projects. ${ }^{26}$

This synthesis of newly appreciated, reprioritized, and system-aligned foundational competencies is quickly becoming central to how we care for patients and populations and is in the process of disrupting and reshaping traditional approaches to medical education and patient care. ${ }^{27,37}$ This movement is gathering steam, and the groundwork is being laid for substantive integration of HSS knowledge into National Board of Medical Examiners board examinations and other high-stakes assessments. The emergence of HSS as a critical link in how we learn and practice is one of the major stories in healthcare, and GIM physicians are ideally positioned to create, support, and lead from UME through CME. ${ }^{38}$

\section{GENERAL INTERNAL MEDICINE AS THE "CONTROL CENTER" FOR SYSTEMS LEARNING}

For medical students and residents to develop as "systems thinkers" and "change agents," they must have the opportunity to work and learn from faculty role models who enact HSS principles in their work and teaching. ${ }^{39,}{ }^{40}$ These role models are often GIM faculty who have become "go-to" individuals to not only manage disease, but also to manage teams of caregivers, facilitate care transitions and information flow, and "quarterback" patient care amongst the continuum of hospital care, post-acute care, palliative care, and home care. ${ }^{41} \mathrm{We}$ view GIM as the "control center" in the health system for acute and chronic illness for many patients who may or may not be concurrently managed by subspecialty colleagues. And as a result, GIM is in the control center for both facilitating and accelerating HSS education with students, residents, and interprofessional faculty (Table 1 which includes examples of clinical-education roles for GIM faculty across HSS areas).

Since GIM faculty educators are well suited to operationalize the work of HSS principles, in the end, they are key role models for the next generation of caregivers. While trainees may eventually choose to practice IM in any number of settings, their educational experience should include an explicit emphasis on systems thinking and HSS, making it possible for core competencies to be employed across health systems. We envision a GIM that is the primary driver of a learning health system and home to physicians who exemplify the importance of HSS for patients and caregivers - doctors for adults, doctors for systems of care, and doctors for the next generation of doctors. But what is currently happening in GIM? What kind of care are GIM faculty modeling? The care that they "grew up" with, or the care that we need our students to grow into? We believe health systems need GIM physicians to facilitate transformation and improve patient outcomes and therefore need to invest in GIM as exemplars of HSS in the workplace, as systems thinkers, and as collaborative, empowered leaders and educators. ${ }^{6,7}$

\section{A CALL TO ACTION FOR GENERAL INTERNAL MEDICINE AND HEALTH SYSTEMS}

GIM faculty are in a pivotal role within academic health systems. Health systems need highly engaged, systemsbased physicians to champion care for patients and health systems with complex issues. Medical students and residents need role models who will not only apply HSS to the care of patients and populations but will also support and lead educational efforts in these areas. GIM faculty who are able to fulfill these roles will help catalyze and accelerate a cycle of change in medical education and systems improvement (Appendix 1). 
Table 1 Health Systems Science Concepts and Representative Examples in General Internal Medicine

\begin{tabular}{|c|c|}
\hline Health systems science $^{a}$ & Representative examples of GIM physicians leading clinical and education initiatives \\
\hline $\begin{array}{l}\text { Healthcare delivery } \\
\text { - Structures of delivery } \\
\text { - Processes of delivery }\end{array}$ & $\begin{array}{l}\text { Clinical: Hospitalist physician co-leads an interprofessional, unit-based quality team that seeks to identify } \\
\text { gaps in quality of care outcomes and develops improved processes for IM patients. } \\
\text { Education: For the internal medicine residency core curriculum, the physician provides consultant } \\
\text { expertise within resident reports focused on the concepts structures and processes of healthcare delivery. }\end{array}$ \\
\hline $\begin{array}{l}\text { Population, public, and social determinants } \\
\text { of health } \\
\text { - Social determinants of health } \\
\text { - Public health } \\
\text { - Population health and improvement }\end{array}$ & $\begin{array}{l}\text { Clinical: Outpatient physician leads a Transitions Program at the health system level, which aims to } \\
\text { proactively identify the social determinants of health they may be associated with poor health outcomes } \\
\text { (e.g., readmissions to the hospital, mortality) for a population of "super utilizers." } \\
\text { Education: For the faculty-level HSS academy (professional development program), the physician } \\
\text { co-creates and leads a session on transitions of care and the implications for social determinants of health } \\
\text { on readmissions and outcomes. }\end{array}$ \\
\hline $\begin{array}{l}\text { High-value care } \\
\text { - Quality principles and dimensions } \\
\text { - Cost and waste } \\
\text { - Evaluation/metrics }\end{array}$ & $\begin{array}{l}\text { Clinical: Palliative care physician identifies high-cost utilization of healthcare services for patients in the } \\
\text { health system during end-of-life care and develops a process for referral to end-of-life care planning and } \\
\text { proactive utilization of healthcare services. } \\
\text { Education: For the 4th-year medical school course, the physician develops and teaches a career } \\
\text { exploration elective on end-of-life planning, costs of end-of-life care, and how to improve quality. }\end{array}$ \\
\hline $\begin{array}{l}\text { Health system improvement } \\
\text { - Improvement principles, processes, } \\
\text { and tools } \\
\text { - Data and measurement } \\
\text { - Innovation and scholarship }\end{array}$ & $\begin{array}{l}\text { Clinical: Geriatrician physician collaborates with members of the Operational Excellence team to } \\
\text { facilitate a root-cause-analysis of low adherence of GIM providers with geriatrics assessment instruments, } \\
\text { which results in a new process for the GIM clinic to improve outcomes for patients. } \\
\text { Education: For the internal medicine residency, the physician co-leads several sessions in the core } \\
\text { curriculum focused on health system improvement principles and change management. }\end{array}$ \\
\hline
\end{tabular}

EHR electronic health record, HSS health systems science, GIM general internal medicine

${ }^{a}$ Framework derived, in part, from several prior publications; additional domains include systems thinking, change management and advocacy, ethics and legal, leadership, and teaming/teamwork $3,7,24,30,31$

There are multiple challenges that exist in fulfilling this agen$\mathrm{da}$, and here, we highlight several challenges and potential strategies that GIM can use to accelerate change (Box 1).

Box 1 Potential Strategies for General Internal Medicine to Advance Health Systems Science Education

- Assess GIM faculty awareness of and engagement in HSS concepts (e.g., surveys, division meeting discussions).

- Review the medical school's core competency framework and HSSrelated competencies.

- Identify local HSS champion (e.g., director of HSS, bridging leader) and provide support for time/skill development.

- Seek to build partnerships with system leaders to articulate potential return on investment of new HSS champions.

- Develop new educational and professional development opportunities for students, residents, and faculty in HSS.

- Identify similarities and differences in student and resident HSS milestones and competencies.

- Develop and employ assessments across the UME-GME continuum. - Support and incentivize faculty efforts to develop HSS curricula at the point of care.

In our experience and as identified in the literature, many faculty have not been formally educated in HSS and express concerns about learning these new skills, often believing they have already acquired these skills from years of everyday practice and/or do not embrace these evolving concepts. ${ }^{2,12}$,
${ }^{42}$ While GIM faculty educators might quickly learn the nuances of a particular system and broader functioning of the healthcare system over time, experience is necessary but insufficient to match learner demands, especially learners who have received foundational training through evolving medical education curricula. Faculty experience does not necessarily predict his/her ability to effectively teach or role model HSS in clinical learning environments. ${ }^{43}$ Failure to provide faculty with educational tools along with the HSS knowledge, skills, and attitudes that they did not encounter in medical school or residency risks creating a hidden curriculum that undercuts our best efforts to align education with system needs. When learners arrive in their clerkships or intern rotations after experiencing robust UME HSS curricula, they need to be met by faculty willing to engage how social determinants of health impact a patient's readmission risk, explore the cost implications of medical decisions, discuss the inherent challenges of measuring quality data, or demonstrate the importance of interprofessional collaborative care. ${ }^{44,45}$

Health systems science must make its way into the toolkit and vernacular of any GIM faculty educator leading change or interfacing with learners. To that end, GIM groups can promote dialog within and amongst faculty targeting HSS 
competencies. ${ }^{46}$ At the microsystem level, this might start with widespread implementation of HSS skill-based workshops within the Division of GIM or medical school. More broadly, it is important to develop and cultivate programs that move beyond individual facets of HSS. Although there is a growing national effort to educate faculty to address gaps in skills, particularly those related to HSS, few evidence-based initiatives have surfaced. ${ }^{6,7,47}$ Several national GIM organizations have begun short, immersive faculty development programs occurring during meeting conferences (e.g., Society of Hospital Medicine Quality and Safety Educators Academy, Association of Chiefs and Leaders of General Internal Medicine LEAD Program). However, these programs are limited in who they can reach, require significant resources, are devoid of local context, and narrowly focus on quality improvement or leadership. ${ }^{48,49}$ For broad-based and accelerated change, divisional strategic plans and aligned initiatives need to include HSS as a primary focus (e.g., hard-wired HSS perspective in all GIM conferences, templated annual review that includes HSS focus).

GIM faculty live professionally in divisions, departments, and academic health systems that shape motivation, behavior, and career paths through leadership and institutional priorities. Providing faculty development opportunities is a start, but not enough. Faculty must be supported in roles that recognize and promote their expertise and influence in both healthcare and educational systems. ${ }^{50}$ Accountability on both sides is crucial. Health systems and organizations must allow for the creation of environments where these skills are allowed to flourish and contribute to clinicians' agency to improve the system rather than be viewed as an add-on to current activities that may further contribute to burnout. ${ }^{51,52}$ While traditional medical education financing has always been reliant on benevolent leadership, faculty interest, profit margins, and alignment of financial resources with the stated academic mission, HSS education holds out the possibility of a truly collaborative commitment with current and future benefits to chief executive officers, department chairs, and frontline faculty. ${ }^{53,54}$ With the goals, values, and desired outcomes of health systems and medical education systems in alignment, faculty can derive professional and personal fulfillment from their sense of contributing towards a shared mission, regardless of their role within the system.

\section{CONCLUSION}

General internal medicine-inclusive of hospitalist, geriatrician, and palliative and outpatient physician-educators - is uniquely poised to contribute to the healthcare and medical education transformation that is already underway. This transformation is occurring at multiple levels, from the way that we educate physicians to the way we care for patients and populations, and it depends significantly on the emerging field of health systems science. GIM faculty work in the "control center" of systems of care and have the potential to impact learners at all levels. We believe that IM-trained faculty physician-educators are in a key position in health system and educational transformation. General internal medicine leaders are well positioned to align with health systems, departments, and medical schools to develop opportunities for faculty development and career enhancement in HSS.

Acknowledgments: The authors thank the students, faculty, and leadership at the Penn State College of Medicine for their contributions and support of the educational programs.

Corresponding Author: Jed D. Gonzalo, MD, MSc; Division of General Internal Medicine, Penn State College of Medicine, Hershey, PA, USA (e-mail: jgonzalo@pennstatehealth.psu.edu).

Funding Information This work at the Penn State College of Medicine was partly funded by the American Medical Association and the Josiah Macy Jr. Foundation.

\section{Compliance with Ethical Standards:}

Conflict of Interest: J.D. Gonzalo is co-editor of the textbooks Health Systems Science (Elsevier, 2016) and Health Systems Science review (Elsevier, 2019).

Ethical Approval: Not applicable.

\section{REFERENCES}

1. Bodenheimer T, Sinsky C. From triple to quadruple aim: care of the patient requires care of the provider. Ann Fam Med 2014;12(6):573-576.

2. Gonzalo JD, Ogrinc G. Health Systems Science: The "Broccoli" of Undergraduate Medical Education. Acad Med 2019;94(10):1425-1432.

3. Skochelak SE, Hawkins RE, AMA Education Consortium. Health systems science. First edition. ed. Philadelphia: Elsevier; 2016.

4. Gonzalo JD, Haidet P, Papp KK, et al. Educating for the 21st-Century Health Care System: An Interdependent Framework of Basic, Clinical, and Systems Sciences. Acad Med 2017;92(1):35-39.

5. Skochelak SE, Hawkins RE, AMA Education Consortium. Health systems science. First edition. ed. Philadelphia: Elsevier; 2017.

6. Lucas B. Getting the improvement habit. BMJ Qual Saf 2016;25(6):400-403.

7. Gonzalo JD, Ahluwalia A, Hamilton M, Wolf H, Wolpaw DR, Thompson BM. Aligning Education With Health Care Transformation: Identifying a Shared Mental Model of "New" Faculty Competencies for Academic Faculty. Acad Med 2018;93(2):256-264.

8. Wachter RM, Goldman L. The emerging role of "hospitalists" in the American health care system. N Engl J Med 1996;335(7):514-517.

9. Wachter RM, Goldman L. Zero to 50,000 - The 20th Anniversary of the Hospitalist. N Engl J Med 2016;375(11):1009-1011.

10. Greene SM, Reid RJ, Larson EB. Implementing the learning health system: from concept to action. Ann Intern Med 2012;157(3):207-210.

11. Greiner A, Knebel E, Institute of Medicine (U.S.). Board on Health Care Services., Institute of Medicine (U.S.). Committee on the Health Professions Education Summit. Health professions education : a bridge to quality. Washington, D.C.: National Academies Press; 2003.

12. Gonzalo JD, Caverzagie KJ, Hawkins RE, Lawson L, Wolpaw DR, Chang A. Concerns and Responses for Integrating Health Systems Science Into Medical Education. Acad Med 2017.

13. ACGME Outcomes Project. Accreditation Council for Graduate Medical Education; 1999.

14. Graham MJ, Naqvi Z, Encandela J, Harding KJ, Chatterji M. Systemsbased practice defined: taxonomy development and role identification for competency assessment of residents. J Grad Med Educ. 2009; 1(1):49-60.

15. Guralnick S, Ludwig S, Englander $\mathbf{R}$. Domain of competence: Systemsbased practice. Acad Pediatr 2014;14(2 Suppl):S70-79.

16. Koh NJ, Wagner R, Newton RC, et al. Detailed Findings From the CLER National Report of Findings 2018. J Grad Med Educ 2018;10(4 Suppl):49-68. 
17. Clinical Learning Environment Review: National Report of Findings 2018. 2018. https://www.acgme.org/Portals/0/PDFs/CLER/CLER_2018_Executive_Summary_DIGITAL_081418.pdf. Accessed 15 Jan 2019.

18. Drolet BC, Brower JP. The Clinical Learning Environment Review (CLER) Program: Moving Beyond Duty Hours. Acad Med 2017;92(2): 141.

19. Weiss KB, Bagian JP, Nasca TJ. The clinical learning environment: the foundation of graduate medical education. JAMA. 2013;309(16):16871688.

20. Quality Improvement \& Patient Safety Competencies. https://www. aamc.org/initiatives/quality/qips/. 2018. Accessed 10 Dec 2018.

21. Behavioral and Social Science Foundations For Future Physicians Association of American Medical Colleges (AAMC). https://www.aamc org/download/271020/data/behavioralandsocialsciencefoundationsforfuturephysicians.pdf. 2011. Accessed 21 Aug 2015.

22. Colbert CY, Ogden PE, Ownby AR, Bowe C. Systems-based practice in graduate medical education: systems thinking as the missing foundational construct. Teach Learn Med. 2011;23(2):179-185.

23. Gonzalo JD, Wolpaw T, Wolpaw D. Curricular Transformation in Health Systems Science: The Need for Global Change. Acad Med 2018;93(10):1431-1433.

24. Gonzalo JD, Dekhtyar M, Starr SR, et al. Health Systems Science Curricula in Undergraduate Medical Education: Identifying and Defining a Potential Curricular Framework. Acad Med 2017;92(1):123-131.

25. Gonzalo JD, Chang ADM, Starr SR, Holmboe E, Wolpaw DR. Health Systems Science in Medical Education: Unifying the Components to Catalyze Transformation. Acad Med (ahead of print). 2019.

26. Baxley EG, Lawson L, Garrison HG, et al. The Teachers of Guality Academy: A Learning Community Approach to Preparing Faculty to Teach Health Systems Science. Acad Med. 2016.

27. Chang A, Ritchie C. Patient-Centered Models of Care: Closing the Gaps in Physician Readiness. J Gen Intern Med 2015;30(7):870-872.

28. Lucey CR. Medical education: part of the problem and part of the solution. JAMA Intern Med 2013;173(17):1639-1643.

29. Skochelak SE, Hawkins RE, AMA Education Consortium. Health systems science. St. Louis: Elsevier; 2016.

30. Starr SR, Agrwal N, Bryan MJ, et al. Science of Health Care Delivery: An Innovation in Undergraduate Medical Education to Meet Society's Needs. Mayo Clin Proc Innov Qual Outcomes 2017;1(2):117-129.

31. Starr SR, Reed DA, Essary A, et al. Science of health care delivery as a first step to advance undergraduate medical education: A multiinstitutional collaboration. Healthc (Amst) 2017;5(3):98-104.

32. Arnold RD, Wade JP. A Definition of Systems Thinking: A Systems Approach. Procedia Comput Sci 2015;44:669-678.

33. Plack MM, Goldman EF, Scott AR, et al. Systems Thinking and Systems-Based Practice Across the Health Professions: An Inquiry Into Definitions, Teaching Practices, and Assessment. Teach Learn Med 2018;30(3):242-254.

34. Gonzalo JD, Graaf D, Kass LE, Promes SB, Wolpaw DR, George DR. Medical Students as Systems Ethnographers: Exploring Patient Experiences and Systems Vulnerabilities in the Emergency Department. Academic Emergency Medicine Education and Training. 2017.

35. McDermott C, Shank K, Shervinskie C, Gonzalo JD. Developing a Professional Identity as a Change Agent Early in Medical School: the Students' Voice. J Gen Intern Med 2019;34(5):750-753.

36. Moser EM, Huang GC, Packer CD, et al. SOAP-V: Introducing a method to empower medical students to be change agents in bending the cost curve. J Hosp Med 2016;11(3):217-220.
37. Djulbegovic B, Bennett CL, Guyatt G. A unifying framework for improving health care. J Eval Clin Pract 2018.

38. LaRochelle JS, Aagaard E. Transformation and Innovation at the Nexus of Health Systems and Medical Education. J Gen Intern Med 2019;34(5):645-646

39. Cruess RL, Cruess SR, Steinert Y. Amending Miller's Pyramid to Include Professional Identity Formation. Acad Med 2016;91(2):180-185.

40. McDermott C, Shank K, Shervinskie C, Gonzalo JD. Developing a Professional Identity as a Change Agent Early in Medical School: the Students' Voice. J Gen Intern Med 2019.

41. Press MJ. Instant Replay - A Quarterback's View of Care Coordination. N Engl J Med 2014;371(6):489-491.

42. Gonzalo JD, Baxley E, Borkan J, et al. Priority Areas and Potential Solutions for Successful Integration and Sustainment of Health Systems Science in Undergraduate Medical Education. Acad Med 2017;92(1):6369.

43. Improving Environments for Learning in the Health Professions: Recommendations from the Macy Foundation Conference. 2018; http:// macyfoundation.org/docs/macy_pubs/June2018_Summary_webfile_7. 20.18.pdf. Accessed 11 Dec 2018.

44. Hunderfund ANL, Dyrbye LN, Starr SR, et al. Attitudes toward costconscious care among US physicians and medical students: analysis of national cross-sectional survey data by age and stage of training. BMC Med Educ 2018;18.

45. Hunderfund ANL, Dyrbye LN, Starr SR, et al. Role Modeling and Regional Health Care Intensity: US Medical Student Attitudes Toward and Experiences With Cost-Conscious Care. Acad Med 2017;92(5):694702.

46. Lee VS, Kawamoto $\mathbf{K}$, Hess $\mathbf{R}$, et al. Implementation of a Value-Driven Outcomes Program to Identify High Variability in Clinical Costs and Outcomes and Association With Reduced Cost and Improved Quality. JAMA. 2016;316(10):1061-1072.

47. Crosson FJ, Leu J, Roemer BM, Ross MN. Gaps in residency training should be addressed to better prepare doctors for a twenty-first-century delivery system. Health Aff (Millwood) 2011;30(11):2142-2148.

48. Myers JS, Tess A, Glasheen JJ, et al. The Quality and Safety Educators Academy: fulfilling an unmet need for faculty development. Am J Med Qual 2014;29(1):5-12.

49. LEAD Program. Association of Chiefs and Leaders of General Interna Medicine 2019; https://www.sgim.org/aclgim-tools\%2D\%2Dprograms/ lead. Accessed 7 May 2019.

50. Gupta R, Sehgal N, Arora VM. Aligning Delivery System and Training Missions in Academic Medical Centers to Promote High-Value Care. Acad Med 2019;94(9): 1289-1292.

51. Egener BE, Mason DJ, McDonald WJ, et al. The Charter on Professionalism for Health Care Organizations. Acad Med 2017:92(8):1091-1099.

52. Shapiro DE, Duquette C, Abbott LM, Babineau T, Pearl A, Haidet P. Beyond Burnout: A Physician Wellness Hierarchy Designed to Prioritize Interventions at the Systems Level. Am J Med 2019;132(5):556-563.

53. Gupta R, Arora VM. Merging the Health System and Education Silos to Better Educate Future Physicians. JAMA. 2015;314(22):2349-2350.

54. Gonzalo JD, Chang A, Wolpaw DR. New Educator Roles for Health Systems Science: Implications of New Physician Competencies for U.S. Medical School Faculty. Acad Med. 2018

Publisher's Note Springer Nature remains neutral with regard to jurisdictional claims in published maps and institutional affiliations. 